\title{
Investigation of the Markets Dynamics Type for a Comparative Analysis of the Investment Instruments Attractiveness
}

\author{
Nataliia Maksyshko \\ Department of Economic Cybernetics \\ Faculty of Economics \\ Zaporizhzhia National University \\ Zaporizhzhia, Ukraine \\ http://orcid.org/0000-0002-0473-7195
}

\author{
Oksana Vasylieva \\ Department of Economic Cybernetics \\ Faculty of Economics \\ Zaporizhzhia National University \\ Zaporizhzhia, Ukraine \\ http://orcid.org/0000-0002-6332-2707
}

\begin{abstract}
The article contributes to solving the problem of choosing the most attractive investment instrument from a variety of alternatives based on a comparative analysis of the dynamics of relevant markets. The nature of the dynamics affects the predictability level of the investor's income and is determined by finding out which hypothesis corresponds to the dynamics: Efficient market hypothesis, Fractal market hypothesis and Coherent market hypothesis. For this purpose, a comparative analysis methodology has been proposed, which is based on the use of statistical analysis methods, combined with methods of complex fractal analysis to identify the presence in the dynamics of deterministic chaos and assess time series characteristics. On the example of three markets, a comparative analysis of three instruments (gold, currency pair of EUR / USD and Bitcoin cryptocurrency) was conducted.
\end{abstract}

Keywords-investment markets, comparative analysis, memory depth, forecast horizon

\section{INTRODUCTION}

Nowadays prospective investors have access to huge amount of information, coming from various sources, leading to virtually unlimited opportunities to choose an investment instrument at the global financial markets. Such an information volume boost is caused by modern infrastructure of investment markets and by the development of digital technologies for transaction implementation. On the one hand, it is a positive trend, and on the other hand, access to large amounts of information requires a proper mechanism for comparing and choosing from a variety of alternatives the most attractive investment object.

Investment markets are complex dynamic systems with many external and internal factors of influence. To understand these systems, today there are several hypotheses describing how the market is functioning. The most famous are: Efficient market hypothesis (EMH) [1]-[2], Fractal market hypothesis (FMH) [3] and Coherent market hypothesis (CMH) [4]. For example, the correspondence of dynamics to the conditions of the EMN involves random walk of the price, and the forecasted income is expected at the level of the average for a particular market. Conversely, the presence of fractal dynamics involves long-term memory of the time series and, on the basis of this, the ability to predict the behavior of the system.
Therefore, it is important to find out and compare the nature and features of the investment markets' dynamics, which are the focus of investors' attention. Recommendations to investors regarding the use of investment instruments depend on the hypothesis which is crucial for describing the dynamics of the relevant market or its segment. Therefore, it is important to find out and compare the nature and features of the investment markets' dynamics, which are the focus of investors' attention.

So, development of the comparative analysis technique of investment markets dynamics in the context of existing market hypotheses, assessment of investment prospects, and developing recommendations on the benefits of investing for different planning horizons are extremely urgent and important tasks.

\section{RELATED WORK}

Each of the aforementioned hypotheses implies appropriate prerequisites for the dynamics of investment markets and uses special methods of diagnostics and analysis.

\section{Consider each of the hypotheses in more detail.}

The basis of EMH is the following preconditions [1]-[2]: all the information is equally accessible and can be immediately taken into account by the market at a fair price, future prices depend only on the new information, future prices are not related to the previous ones, the impact of the information is linear, market participants are rational and homogeneous (they are equally not risk-averse and have the same investment horizons). Within this hypothesis, linear models, probabilistic calculations and statistical analysis are used.

Main characteristics of a fractal market are [3]: the main thing in the market is not a fair price, but liquidity, prices have a memory of previous values, locally the market is random, but globally - determined, but the dynamics of the market is nonlinear, investors differ in investment horizons. For diagnostics and analysis, nonlinear models, fractal mathematics and chaos theory tools are used.

The Coherent market hypothesis combines the two previous hypotheses and represents a nonlinear statistical 
model. According to $\mathrm{CMH}$, markets go through four phases: random walk, unstable transition, chaos, and coherence [4].

All the above mentioned hypotheses have been arisen and developed in studies of stock markets [1]-[4]. However, the local stock markets assessment of the correspondence to existing hypotheses remains relevant today [5]-[12]. But now the scope of their application has considerably expanded, along with stock markets, dynamics analysis is actively conducted for the currency markets [13]-[15], deposits [16] and cryptocurrency [17].

Some work is directly related to the use of statistical (for proving the EMH) [6]-[9], [12], [13] or fractal (for proving the FHM) [10], [15] analysis tools. Other studies are devoted to a specific analysis tool, for example, Fourier Unit Root Test [5] or Hurst exponent [17].

In this work it is proposed to approach the choice of tools for analysis in a comprehensive way and to use both statistical and fractal methods. The purpose of this study is not so much a determination to the type of the market, but the allocation of important characteristics of the market. Financial markets are complex systems, so it is difficult to put them in a clear framework of a theoretical model. And as it is shown below, one and the same market can demonstrate different types of dynamics not only at different time intervals, but also when choosing different time scales.

It determines the importance of a comprehensive analysis of the investment markets dynamics to highlight their crucial characteristics. These characteristics can be used to compare and select a suitable investment tool for different forecasting horizons.

\section{MATERIALS AND METHODS}

It was decided to consider the following investment instruments: precious metals market, Forex currency market and cryptocurrency market. All of them are both high-tech and affordable, which means the presence of information technologies and applications for a wide range of individual investors.
To represent each of the markets, it is proposed to study correlation matrices demonstrating the relation between the prices dynamics of investment objects. If the absolute values of the correlation are high (approximated to 1), then, firstly, it gives an opportunity according to the dynamics characteristics of the one object to draw a conclusion on the other investment objects dynamics of this group, and secondly, the high level of connection between investments increase the risks of an investor when working with related assets (in this case, it is expedient to work with only one investment object in the given direction).

The subject of the analysis are the daily values of the prices and the profitability of the gold, the currency pair EUR/USD and the Bitcoin for the period from January 2012 to June 2019. The research in this work was conducted in two directions: the study of the price behavior of the investment object and its profitability.

Figure 1 shows steps and methods used to research and compare the investment markets. It should be noted that the above steps were applied both for the time series (TS) of the prices, and to the TS of the profitability of the relevant markets.

In step 2.2 of Figure 1 the compliance with the normal distribution is checked. According to $\mathrm{EMH}$, investment instruments prices already take into account past information, therefore the next price change is influenced only with the new information [2]. Hence, all occurring on the market changes are not related events. It follows from the central limit theorem [18] that the distribution of a large number of random independent variables converges to normal distribution. So, by checking the hypothesis of normal distribution (step 2.2 of Figure 1), the hypothesis of an effective market is checked.

The normality of the distribution was analyzed with [18]:

- verification for the equality of average and median;

- check for the matching of the asymmetry;

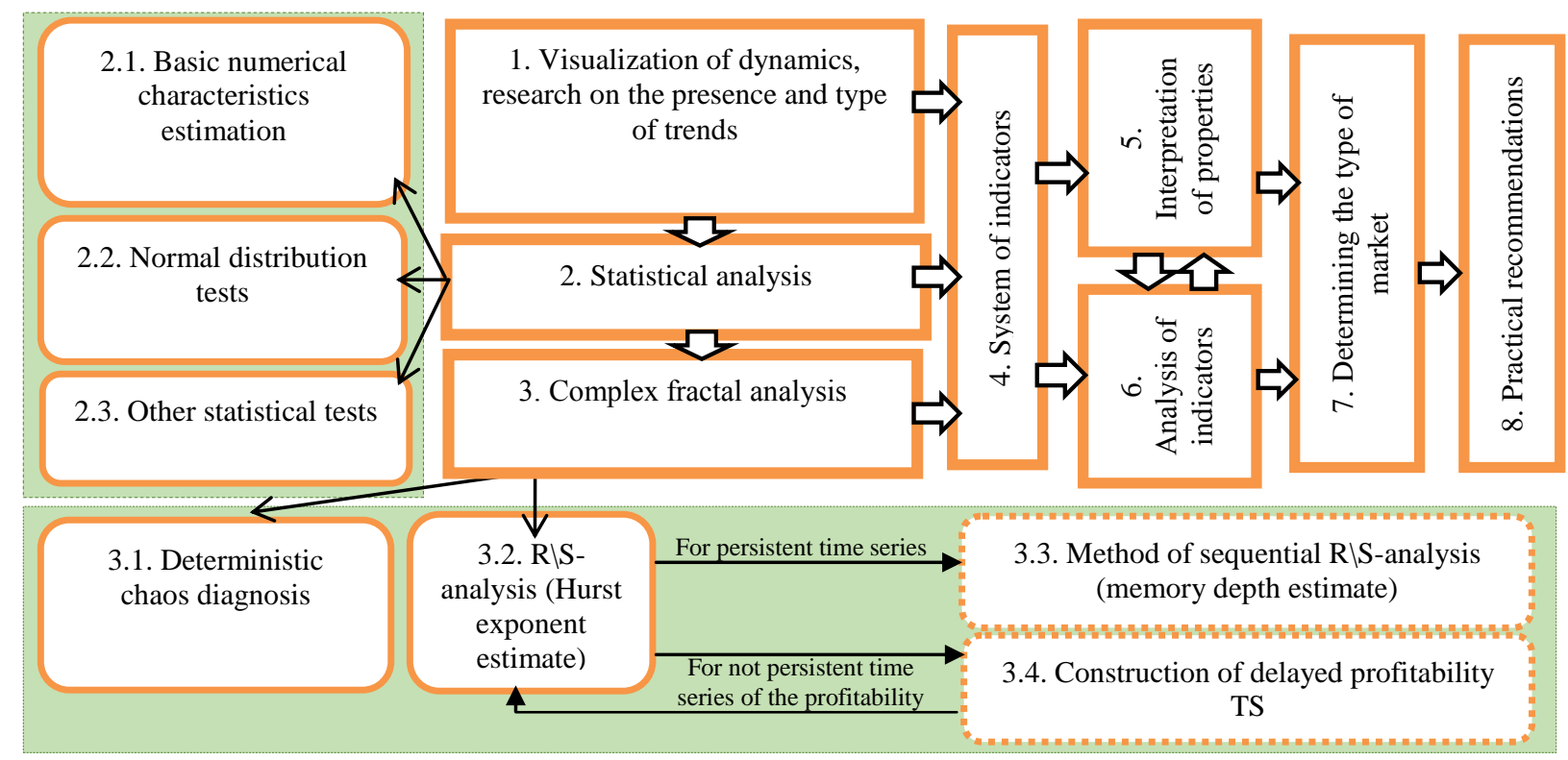

Fig. 1. Investment market comparative analysis technique steps 
- check the excess coefficient;

- Kolmogorov-Smirnov Test;

- Shapiro-Wilk test.

In addition, there are various statistical tests checking the availability of some characteristics of the weak form of efficient market, such as the independence between events, the stationarity of a time series, the random nature of price changes or the study of variances.

In step 2.3, the following tests were carried out and the following methods were applied: constructing regression equations and checking them for statistical significance; checking for auto-correlation; Durbin-Watson Test, Breusch-Godfrey serial correlation LM-test, Augmented Dickey-Fuller Unit Root test (ADF test) and Runs test. The methodology and the obtained results are presented in [19].

In step 3.2, the Hurst exponent is calculated, it allows to determine the presence of memory (persistence) in a TS [3].

For diagnostics of deterministic chaos (step 3.1 of Figure 1) the following tests were applied: drifting attractor test, Gilmore's graphic test, construction of pseudo-phase space [20]. The results of the tests allow to assert that time series of prices and profitability for selected investment objects have a fractal (that is, nonlinear) dynamics.

If the Hurst exponent indicates memory availability, then in step 3.3, to determine the depth of memory, we use the method of sequential RIS-analysis [21]. The result of this method is the construction of a memory depth fuzzy set:

$$
L(i)=\left\{(l, \mu(l)), l \in L^{0}\right\}
$$

where $L(i)$ is a fuzzy set of memory depth for TS(i), $l$ is the value of the sequence number of the trend change point for TS, and $L^{0}=\{l\}$.

In step 3.4 for the profitability time series with the Hurst exponent close to 0.5 , we construct the time series of the delayed profitability by the formula: $\mathrm{p}_{s}=\frac{\left(\mathrm{v}_{(\mathrm{t}+s)}-\mathrm{w}_{\mathrm{t}}\right)}{\mathrm{w}_{\mathrm{t}}} * 100 \%$, where $\mathrm{v}(\mathrm{t})$ - the price of the investment instrument at a day $\mathrm{t}$; $\mathrm{s}-$ is a lag value. Then profitability time series is equal to: $P_{s}(i)=\left\langle p_{s}(i)\right\rangle_{s} i \in\left\{Z_{s} F_{s} B\right\}$, where $Z$ - gold; F - currency pair EUR/USD, B - cryptocurrency Bitcoin.

According to performed calculations, profitability TS may not have memory (Hurst exponent is close to 0.5), however, with the growth of the time lag, time series of delayed profitability become persistent.

For each of those time series, we calculated the Hurst exponent, until we determine the value of $\mathrm{s}$ at which the time series acquires memory (persistence).

\section{RESULTS}

To apply the steps and methods shown in the Fig. 1 and described in the previous section, we have determined the investment objects that will be the subject of the study. The Table I shows the relationship between prices for precious metals. From the Table I, it can be noted that the dynamics of prices for precious metals is not strongly interdependent, except for silver and platinum (correlation coefficient 0.76(9)).

TABLE I. CORRELATION MATRIX OF THE PRECIOUS METALS MARKET BASIC TOOLS

\begin{tabular}{|c|c|c|c|}
\hline Precious metal & Gold & Silver & Platinum \\
\hline Gold & 1 & 0,597546 & 0,197065 \\
\hline Silver & 0,597546 & 1 & 0,769999 \\
\hline Platinum & 0,197065 & 0,769999 & 1 \\
\hline Palladium & 0,498924 & $-0,06401$ & $-0,2124$ \\
\hline
\end{tabular}

The palladium price dynamics is the least associated with the dynamics of other metals from its group. The price dynamics of gold is correlated with the price of silver (the correlation coefficient is 0.598 ), but practically independent of the price of platinum (the correlation coefficient is 0.197). However, given the popularity and demand for individual precious metals, as well as the fact that gold is the oldest investment object that, in the digital economy, has been transformed into a modern high-tech financial instrument, the gold market was chosen for further analysis.

Table II shows the interdependence of the dynamics of major currencies. The table demonstrates that the currency price dynamics is largely interconnected. This indicates an increase in the risk of creating a portfolio of different currencies. In addition, conclusions drawn from the nature of the dynamics of one currency pair will, to a greater or lesser extent, characterize other currency pairs.

TABLE II. CORRELATION MATRIX OF THE CURRENCY MARKET BASIC TOOLS

\begin{tabular}{|c|c|c|c|c|}
\hline Currency & GBP/USD & USD/JPY & EUR/USD & AUD/USD \\
\hline GBP/USD & 1 & $-0,0351$ & 0,66995 & 0,70719 \\
\hline USD/JPY & $-0,0351$ & 1 & $-0,5949$ & $-0,5240$ \\
\hline EUR/USD & 0,66995 & $-0,5949$ & 1 & 0,874497 \\
\hline AUD/USD & 0,70719 & $-0,5240$ & 0,874497 & 1 \\
\hline USD/CHF & $-0,7521$ & 0,42208 & $-0,80055$ & $-0,80754$ \\
\hline
\end{tabular}

In order to determine the currency that best describes the dynamics of foreign exchange markets in general, consider Table II in more detail. According to the correlation coefficients, the currency pair that is the least connected with other currencies is a pair of US dollars (USD) to the Japanese yen (JPY), with the strongest link established between the yen and the euro (correlation coefficient of 0.595). In comparison to other currencies, the pair EUR/USD also has rather strong links, so it was chosen for further analysis.

The most closely interrelated is the dynamics of cryptocurrencies (see Table III). Given the high correlation coefficients, for the further analysis only one cryptocurrency was chosen - Bitcoin - as the most important and most widespread cryptocurrency (the specific weight of the Bitcoin capitalization exceeds half of the total market capitalization of all cryptocurrencies (at least as for June 2019).

TABLE III. CORRELATION MATRIX OF THE CRYPTOCURRENCY MARKET BASIC TOOLS

\begin{tabular}{|c|c|c|c|}
\hline Cryptocurrency & ETH*/USD & BTC**/USD & XRP***/USD \\
\hline ETH/USD* & 1 & 0,886686 & 0,912979 \\
\hline BTC/USD** & 0,886686 & 1 & 0,878988 \\
\hline XRP/USD*** & 0,912979 & 0,878988 & 1 \\
\hline ZEC/USD $* * * *$ & 0,897226 & 0,786186 & 0,939481 \\
\cline { 1 - 2 }
\end{tabular}

*-Ethereum; **-Bitcoin; ***-Ripple; $* * * *-Z c a s h$ 
Thus, for the comparative analysis, three investment objects have been selected: gold (Z), currency pair EUR / USD (F), and cryptocurrency Bitcoin (B).

The steps and methods shown in the Fig. 1 and described in the previous section were applied to daily prices time series of the gold, the currency pair and the Bitcoin for the period from January 2012 to June 2019. Graphical representations of price dynamics are shown in the Figure 2:.
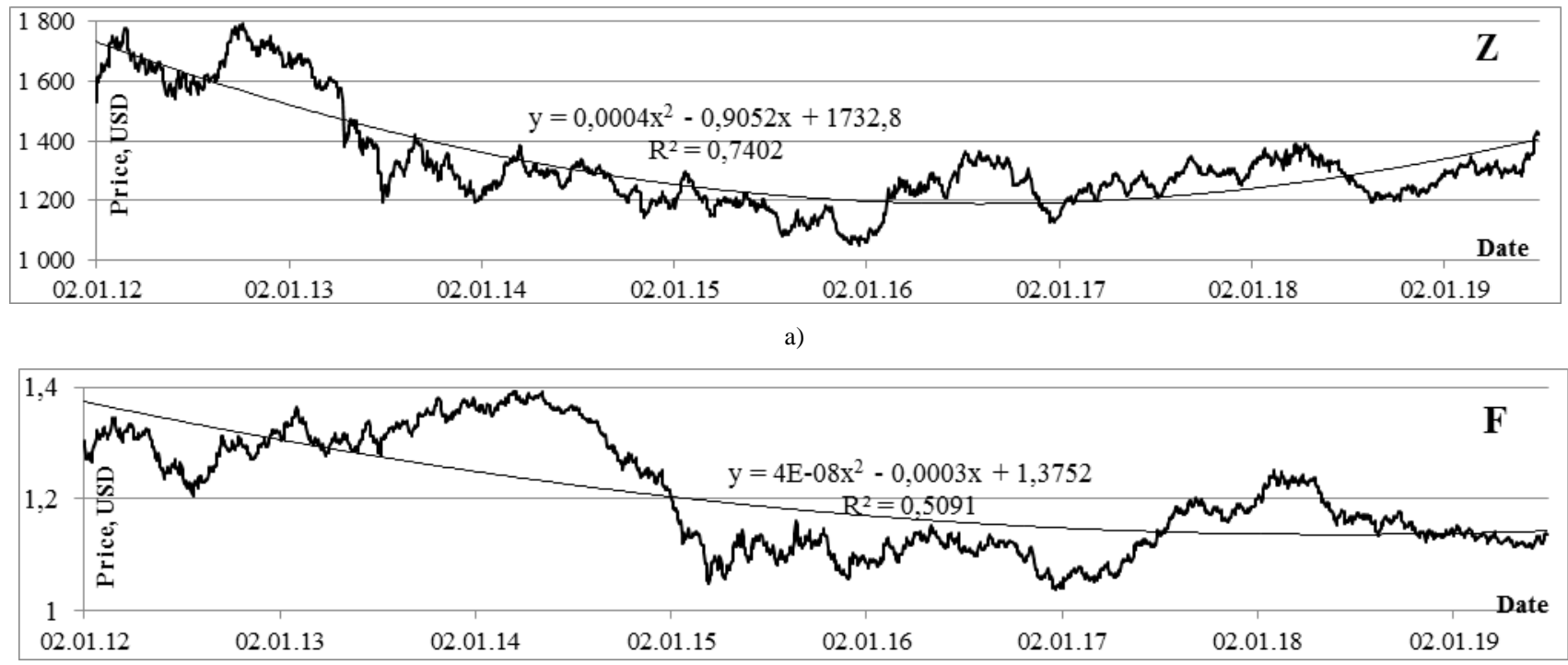

b)

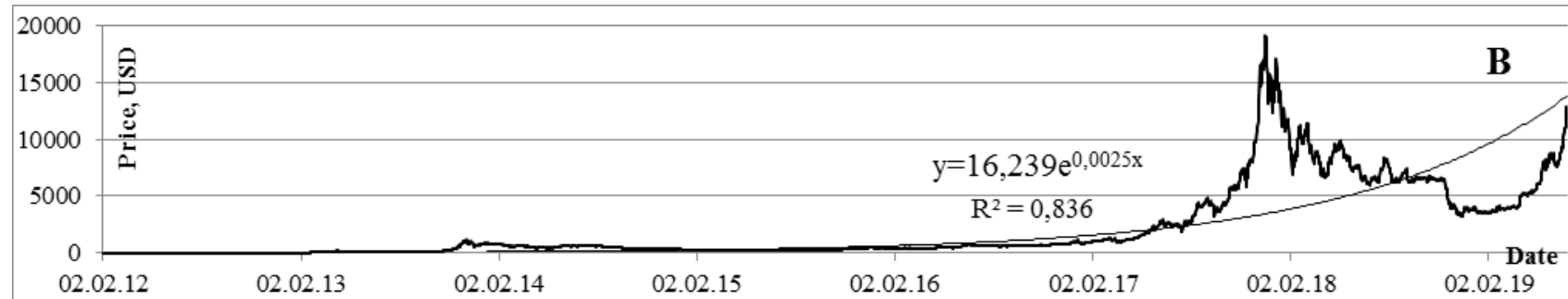

c)

Fig. 2. Price dynamics for the period from January 2012 to June 2019: a) gold; b) currency pair EUR/USD; c) Bitcoin

The time series were studied for the presence and type of trends. The gold is best described with a polynomial trend $\left(\mathrm{R}^{2}=0.74\right)$, the Bitcoin is described with an exponential trend $\left(\mathrm{R}^{2}=0.84\right)$, and the currency pair cannot be described with any of the simple trends $\left(\mathrm{R}^{2}\right.$ of all studied trends is less than 0.51 ).

At the step 2.1 (basic numerical characteristics estimation) it turned out that Bitcoin prices differ from gold and currency pair prices by greater volatility (indicators of variation and oscillations are tens of times larger).

Then the type of distribution was analyzed for both the whole series and particular periods. As a result, it is established that none of the studied series can be described by a normal distribution. Most of the features of the normal distribution are available in the time series of the currency prices for the period from January 2015 to June 2019 (calculated mean value and excess is statistically significant for normal distribution).

The tests on a weak form of market efficiency show positive results for all time series of the prices, except the Dickey-Fuller test (ADF) and the Variance-Ratio test (VRtest) for the Bitcoin dynamics for the last year of research [6].
At the step 3 (fractal analysis), application of tests for deterministic chaos detection has shown that the time series of prices for selected investment objects have a fractal (that is, nonlinear) dynamics. Hurst exponent $(\mathrm{H}(\mathrm{Z})=0.96$, $\mathrm{H}(\mathrm{F})=0.96, \mathrm{H}(\mathrm{B})=0.94$ respectively) indicates that they have long-term memory, and as a result of the application of the sequential $\mathrm{R} \backslash \mathrm{S}$-analysis method via (1).

Graphical representations of the memory depth fuzzy set for each time series are shown in the Figure 3.

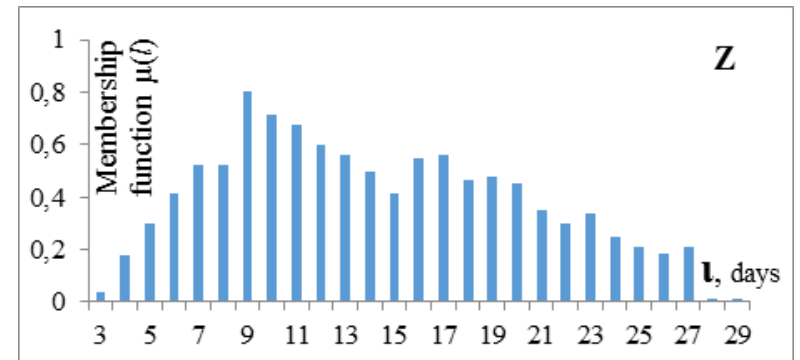

a) 


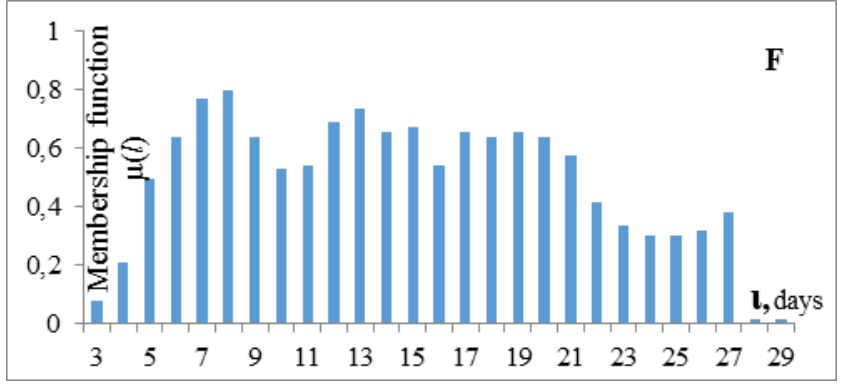

b)

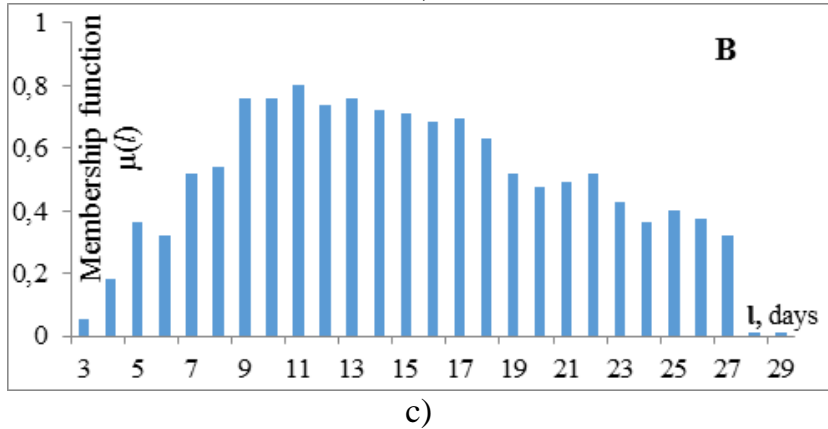

Fig. 3. Fuzzy set of memory depths $\mu$ for the TS of:

a) the gold - (Z); b) EUR/USD - (F); c) Bitcoin - (B)

Analogously the analysis of the profitability time series was conducted.

A comparison of relevant statistical indicators has revealed that standard deviation and range of Bitcoin profitability significantly exceeds the corresponding indicators of the gold and the currency pairs. It shows substantial profits for investors and high risks associated with it. Analyzing the form of distribution, it should be noted that none of the profitability time series corresponds to the normal distribution. Similar to the time series of the price, the closest to the normal distribution is distribution of the currency profitability (average and asymmetry meets the requirements of normal distribution).

Fractal analysis of the profitability of the investment instruments indicates the randomness of time series. The Hurst exponents for the profitability time series are: $\mathrm{H}(\mathrm{Z})=0.58, \mathrm{H}(\mathrm{F})=0.60$ and $\mathrm{H}(\mathrm{B})=0.65$. The application of deterministic chaos tests confirmed that there were no signs of fractality in the selected time series. In this connection, a family of profitability time series with a certain lag was constructed and investigated [3]. The character of the dynamics of profitability varies depending on the magnitude of the time lag (Table IV) and, as it grows, the time series acquire the properties of persistence (the property of memory).

TABLE IV. HURST EXPONENT FOR PROFITABILITY TIME SERIES DEPENDING ON THE VALUE OF LAG

\begin{tabular}{|c|c|c|c|}
\hline \multirow{2}{*}{ Value of lag, s } & \multicolumn{3}{|c|}{ Hurst exponent for profitability time series } \\
\cline { 2 - 4 } & $\boldsymbol{Z}$ & $\boldsymbol{F}$ & $\boldsymbol{B}$ \\
\hline 5 & 0,716726 & 0,74087 & 0,783976 \\
\hline 10 & 0,769639 & 0,788749 & 0,829416 \\
\hline 15 & 0,797009 & 0,817086 & 0,846172 \\
\hline 21 & 0,823865 & 0,847899 & 0,854783 \\
\hline 30 & 0,844634 & 0,874549 & 0,865514 \\
\hline 42 & 0,860378 & 0,895566 & 0,875857 \\
\hline
\end{tabular}

The fastest persistence is acquired by Bitcoin with a lag value of 10 days and the longest one is by gold with a lag value of 21 days (Fig.4).

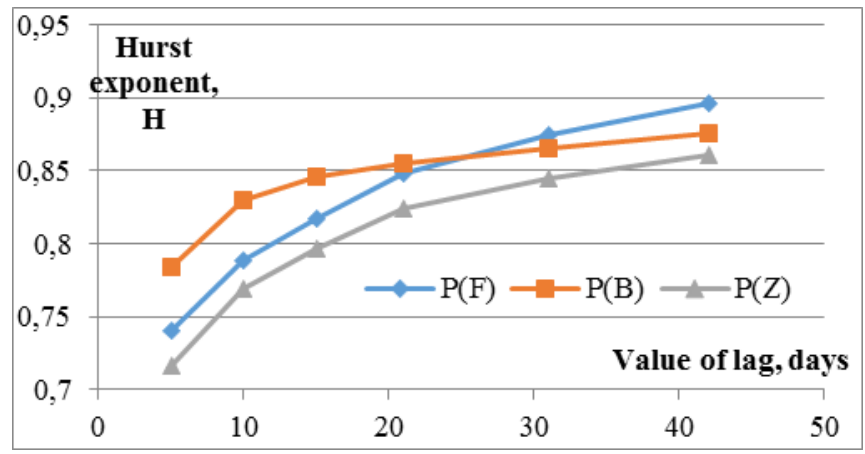

Fig.4. Hurst exponent depending on the value of lag

Fuzzy memory depth sets for time series with a high value of Hurst exponent (greater than 0.85) are shown in Figure 5.

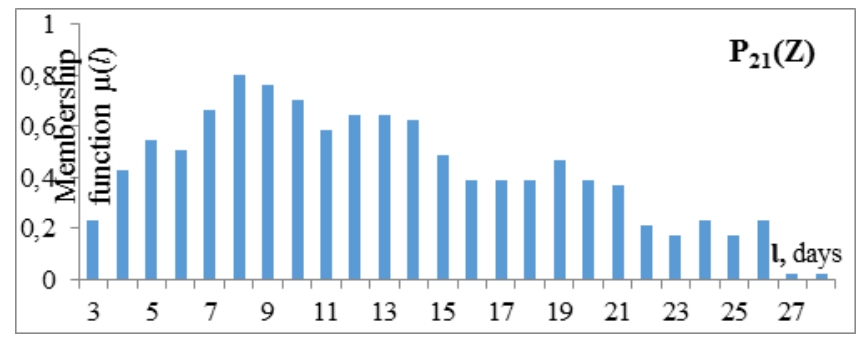

a)

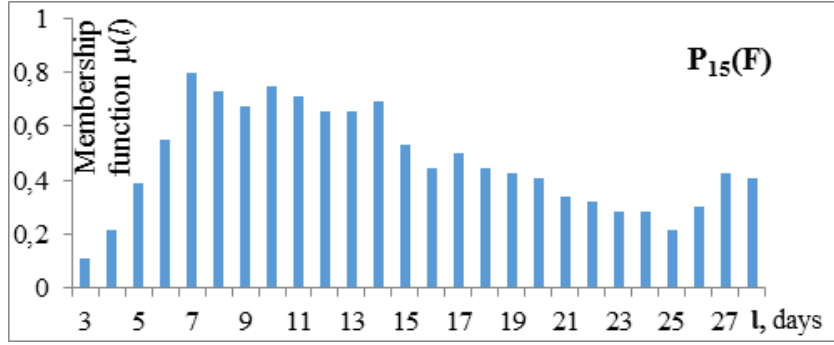

b)

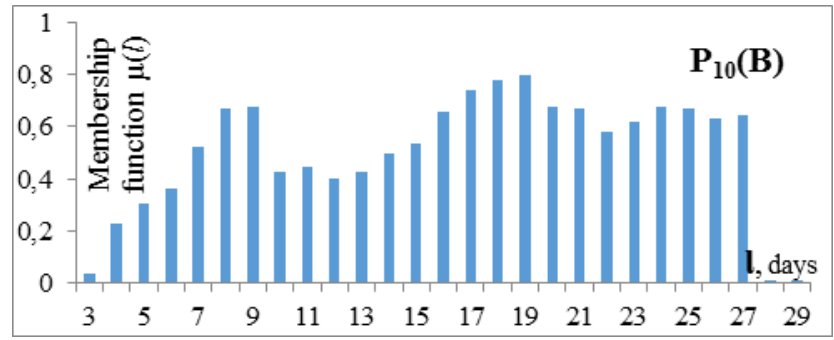

c)

Fig. 5. Fuzzy set of memory depths $\mu$ for the profitability time series of: a) the gold, lag is 21 days $-\mathrm{P}_{21}(\mathrm{Z})$; b) EUR/USD, lag $15-\mathrm{P}_{15}(\mathrm{~F})$; c) Bitcoin, lag $10-\mathrm{P}_{10}(\mathrm{~B})$

It can be noted that, according to the results of the study, the currency market is the most consistent with the efficiency hypothesis. In addition, it is the least volatile market. Similar conclusions can be drawn about the dynamics of the price of gold, although the volatility of the gold price is greater. 


\section{CONCLUSION}

Comparative analysis technique proposed in the paper integrates the tools and various diagnostic tests to determine the crucial characteristics of each studied market. The presented technique of comparative analysis has been tested on three investment markets: the precious metals market (for example, the gold market), Forex currency market (EUR / USD currency pair) and the cryptocurrency market (Bitcoin).

Application of the method to three investment markets has shown that the currency and the gold markets are highly liquid and informative, they are attended by investors with different horizons of forecasting, are stable and do not have significant fundamental changes, fluctuations in prices within a certain range. The slightest volatility is typical for the currency market of EUR/USD, but it is characterized by the slightest excess and smaller "thick tails." Despite the fact that the frequency distribution of the price and profitability does not meet the normal, statistical tests do not reject the hypothesis of the random walk of the gold and currency prices. Therefore, short-term forecasting of price dynamics by quantitative and technical analysis methods is ineffective. Investigation of the delayed profitability time series for the presence of persistence have shown that the gold prices are characterized by the largest time lag, which is 21 days. In a high-frequency and high-tech market (operations can be completed within one day), this is a period that can be attributed to the long-term. For the currency market the lag is 15 days. Also, the depth of time series memory was calculated, which can be used as a parameter for creating a prediction model. Thus, it should be noted that in the short term the gold and the currency market is low-predicted, the prices of these instruments are followed by accidental wandering; therefore, for rapid response to a possible change in the range of values, it is necessary to give preference to fundamental analysis: to carefully monitor the news and the general information background. The gold and currency markets are best suited to the needs of medium and longterm investment.

The Bitcoin price dynamics relative to the US dollar is the most volatile, indicating the potential yield and significant risks of this investment instrument. This market is the worst described with the EMH in the weak form. The period of exponential growth indicates an outrageous mood on the market, resulting from the concentration of investors with the same short-term investment horizon. This led to liquidity problems, reflected in a sharp change in the trend of growth to a decline in December 2017 (see Fig. 2) and uncertainty in the market. The Bitcoin time series are best described by the Coherent market hypothesis, namely, the coherent phase for the exponential growth period and the transition phase for 2018. All the aforementioned, as well as the lack of fundamental information, make it impossible for the medium and long-term forecasting of the Bitcoin market. However, the analysis of delayed profitability time series allowed setting the period at which the profitability time series of Bitcoin acquires persistence (10 days) and is suitable for prediction.

Thus, the results of comparative analysis technique allowed developing practical recommendations to an investor: to compare the markets by their degree of predictability and to determine the best investment horizons for each market. The results will also be used in the further development of forecast models for selected investment instruments.

\section{REFERENCES}

[1] E. F. Fama, "Efficient capital markets: a review of theory and empirical work," Journal of Finance, no. 25, pp. 383-417, 1970.

[2] E. F. Fama, "Efficient capital markets .2," Journal of Finance, vol. 46, no. 5, pp. 1575-1617, Dec 1991, Doi: 10.2307/2328565.

[3] E. Peters, Fractal Market Analysis. Applying Chaos Theory to Investment and Analysis. New York, USA: John Wiley \& Sons, Inc., 1994.

[4] T. Vaga, "The Coherent Market Hypothesis," Financial Analysts Journal, vol. 46, pp. 36-49, November/December 1990.

[5] F. Gümüs, and F. Zeren, "Analyzing the Efficient Market Hypothesis with the Fourier Unit Root Test: Evidence from G-20 Countries," Ekonomski horizonti, vol. 16, no. 3, pp. 225-237, 2014.

[6] N. Gupta, and A. Gedam, "Testing of Efficient Market Hypothesis: a study on Indian Stock Market," Journal of Business and Management, vol. 16, iss. 8, pp. 28-38, 2014.

[7] C. Chen, and M. Metghalchi, "Weak form market efficiency: Evidence from the Brazilian stock market," International Journal of Economics and Finance, vol. 4, no. 7, pp.. 22-32, 2012.

[8] I. E. N. Ananzeh, "Testing the weak form efficient market hypothesis: Empirical evidence from Jordan," International Business and Management, vol. 4, no. 2, pp. 119-123, 2014.

[9] M.O. Onyemachi, "Weak-form market efficiency, estimation interval and the Nigerian stock exchange: empirical evidence," International Academy of Business Review, vol. 3, no.1, pp.42-61, Fall 2016.

[10] E. Onali, and J. Goddard, "Are European equity markets efficient? New evidence from fractal analysis," International Review of Financial Analysis, vol. 20, pp. 59-67, 2011.

[11] X. Y. Wang, T. Lei, Z. Liu, and Z. B. Wang, "Long-memory Behavior Analysis of China Stock Market Based on Hurst Exponent," in 29th Chinese Control And Decision Conference (CCDC), Chongqing, PEOPLES R CHINA, May 28-30 2017, in Chinese Control and Decision Conference, 2017, pp. 1709-1712.

[12] M. R. Borges, "Efficient market hypothesis in European stock markets," (in English), European Journal of Finance, Article vol. 16, no. 7, pp. 711-726, 2010. Doi: 10.1080/1351847x.2010.495477.

[13] M. A. Çiçek, "Cointegration Test for Turkish Foreign Exchange Market Efficiency," Asian Economic and Financial Review, no. 4(4), pp. 451-471, 2014.

[14] J. Ibrahim, and H.A. Ghani, "Weak Form of Foreign Exchange Market in the Organisation for Economic Cooperation and Development Countries: Unit Root Test," International Journal of Business and Management, no.6(6), pp.115-122, 2011.

[15] S. Erokhin and O. Roshka, "Application of fractal properties in studies of financial markets," in International Scientific Conference on Business Technologies for Sustainable Urban Development ( $S P b W O S C E)$, Peter Great Saint Petersburg Polytechn Univ, Inst Ind Management Econ \& Tr, St Petersburg, RUSSIA, Dec 20-22 2017, vol. 170, in MATEC Web of Conferences, 2018. Doi: $10.1051 /$ matecconf/201817001074.

[16] I. Ivanchenko, "Methods for testing the efficiency of the financial market," Financial Analytics: Science and Experience, no.21 (255), pp. 58-68, 2015

[17] L. Kristoufek, "On Bitcoin markets (in)efficiency and its evolution," Physica a-Statistical Mechanics and Its Applications, vol. 503, pp. 257-262, Aug 2018. Doi: 10.1016/j.physa.2018.02.161.

[18] O.O. Zamkov, A.V. Tolstopyatenko, and Yu.N. Cheremnykh, Mathematical methods in economics. Moscow, Russia: MGU im. Lomonosova , 1999.

[19] O.V. Vasylieva, and N.K Maksyshko, "Comparative analysis of investment instruments dynamics in the context of the efficient market hypothesis," Scientific Notes of Ostroh Academy National University, "Economics" series, no.40/2019, pp. 200-206, 2019.

[20] L. N. Sergeeva, Nonlinear Economy: models and methods: Monograph. Zaporizhzhia, Ukraine: Polihraf, 2003.

[21] N.K. Maksyshko, Modeling of economics by methods of discrete nonlinear dynamics: Monograph. Zaporizhzhia, Ukraine: Polihraf, 2009. 